\title{
Effect of pH and API Gravity on the Water-in-Oil Emulsion Stability
}

\section{OLORO, J}

\author{
Department of Petroleum and Gas Engineering, Delta State University, Abraka, Nigeria
}

\section{Email: joloroeng@yahoo.com}

\begin{abstract}
Water-in-oil emulsion is serious problems in the industry since it affects oil production negatively and cost huge sum of money to treat. To select a demulsification process for an emulsion problem, it is very important that one should know the condition that favors emulsion stability, once this is established, treatment procedure can be followed to achieve the desire result. In this study, water-in-oil emulsion was formulated with crude samples from various wells (Oredo tank B, Usan and Atala) ensuring they have different API values, their API values are 45, 27.4 and 34 respectively. Also, Usan crude was formulated with water at varying $\mathrm{pH}$ of 2.34, 7 and 12.7. The results show that Usan crude with lower API gravity broke out $90 \mathrm{ml}$ of oil in 138.5 hours (about six days) while Atala and Oredo broke out $6.0 \mathrm{ml}$ and $2.5 \mathrm{ml}$ respectively. This shows that the effect of API gravity is directly proportional to the stability. Also, the results collected from the Usan when subjected at varying $\mathrm{pH}$ values shows, $65 \mathrm{ml}$ of crude was regained from the emulsion when the $\mathrm{pH}$ is 2.4 (acidic), $35 \mathrm{ml}$ of crude was recovered when the emulsion formulated with distilled water with a $\mathrm{pH}$ of 7 (neutral) while $14.6 \mathrm{ml}$ was recovered when the $\mathrm{pH}$ is 12.3 (alkaline). Hence from the conducted experiment it was noted that high $\mathrm{pH}$ value favors stability of the oil emulsion, while low $\mathrm{pH}$ value is unfavorable for oil emulsion stability.
\end{abstract}

\section{DOI: https://dx.doi.org/10.4314/jasem.v22i6.14}

Copyright: Copyright $@ 2018$ Oloro. This is an open access article distributed under the Creative Commons Attribution License (CCL), which permits unrestricted use, distribution, and reproduction in any medium, provided the original work is properly cited.

Dates: Received: 25 April 2018; Revised: 30 June: 2018; Accepted: 05 July 2018

Key words: Emulsion; Gravity, pH, Oil, Water

Emulsions have been of great interest due to their occurrence in everyday life. It is a fine dispersion of water-in-oil or oil-in-water with drop sizes usually in the micron range (Joblom, 2001). It has the tendency to resist changes in its properties over time; the more stable the emulsion, the more slowly its properties changes.

In the oil industry, the techniques of emulsion and blending with lighter crude oil have been used as a common techniques to transport the heavy crude oil through reducing the viscosity, as the traditional pipelining by heating from the reservoir to the refinery is not a normal approach due to some drawbacks with respect operation cost (Ashrafizadeh and Kamran 2010). However, there are several hindrances with the emulsion approach with respect to selection and the cost of surfactant, efficiency of surfactant in stabilizing the emulsion during transportation and separation once the end point is reached (Shadi et al., 2010). Another problem associated to emulsions, their formation is costly in term of chemical used, production losses, as well as an environmental problem in case of oil-spillage (Mingyuan et al., 1992). Examples of emulsions include vinaigrettes, homogenized milk and some fluids for cutting metal. Graphene and its modified forms are also example of recent unconventional surfactants helping in stabilizing emulsion systems (Kumar, et al., 2016). Reza, et al, 2016, paper was on demulsification methods of water in oil and oil in water emulsions in petroleum industry, in their paper they looked at some important parameters affecting the demulsification. The purpose of this study is to determine the effect of $\mathrm{pH}$ and API gravity on the water-in-oil emulsion stability.

\section{MATERIALS AND METHODS}

Sample Collection: The crude oil used for this research work was collected from various wells. Many of them were sourced for but three samples were selected due to API values differentials. The three samples used for this work with their API gravity values are as follows: Orede Tank B from NPDC, A subsidiary of NNPC. Edo state; Atala Crude oil from Nigeria Agip Oil Corporation (NAOC), Delta state and Usan Crude oil from Nigeria Agip Oil Corporation (NAOC), Delta state.

Determination of API Gravity of the sample: The API gravity of the crude oil samples were determined using density bottle method by weighing empty density bottle with its stopper, the bottled was filled with water weighed. The next step was to fill the bottle with crude and weighed. The weight of water and various samples 
was calculated. And the relative density or specific gravity (S.G) of the three samples were computed using the following formula was determined.

S.G. $=\frac{\text { Weight of substance }}{\text { Weight of equal volume of water }}$

NB: The specific gravity obtained is called specific gravity at test condition. Hence, specific gravity at standard condition will be employed to compensate for $60^{\circ} \mathrm{F}$ as stipulated by the American Petroleum Institute (API Code RP 45H).

S.G at standard condition is calculated with the following equation.

$$
\begin{gathered}
S \cdot G_{S T D}=S \cdot G_{T T}+4 \times 10^{-4} \pm \Delta T \\
S \cdot G_{S T D}=S \cdot G_{T T}+3.5 \times 10^{-4} \pm \Delta T
\end{gathered}
$$

When S.G $_{\mathrm{TT}}$ is between 0.792-0.839

$$
A P I=\frac{141.5}{S . G @ 60^{\circ} \mathrm{F}}-131.5
$$

Formulation of Emulsion: The following procedures were followed during the emulsification process. Emulsion samples are formed based on the scope of work at hand, hence the following steps were taken:

Step 1: All the materials are made ready as stated above. Step 2: $100 \mathrm{ml}$ of water was measured with the use of a measuring cylinder and $2 \mathrm{ml}$ of an emulsifier measured with the use of a syringe and blended for 3 minutes, before measuring a $100 \mathrm{ml}$ of the crude oil sample which was gradually turned into the blender already containing water and an emulsifier, the mixture was blended for another 3 minutes. Stable emulsion was formed. Crude oil and water ratio is 50:50 (v/v). Step 3: The emulsion prepared was checked if it was an oil-in-water or water-in-oil emulsion. To check the nature of emulsion formulated, a filter paper was placed on a work bench and with the aid of a syringe, a $5 \mathrm{ml}$ of the emulsion is sucked and drops of the emulsion was placed on the filter paper.

To prove that the emulsion is water-in-oil, the drop of the emulsion on the filter paper is seen not to disperse in big size, but if it is oil-in-water emulsion, the emulsion is dispersed all over the filter paper. (Nuruul. and Abdurrahman, 2011). But for this work, the emulsion was seen to disperse on small spots which infer it is a water-in-oil emulsion. Step 4: Step 2 and 3 were repeated for the other two samples.

Determination of effect of $\mathrm{pH}$ on Emulsion stability: Step 1: In the formulation of emulsion for effect of $\mathrm{pH}$ on the stability of crude, three (3) emulsion was prepared using Usan crude in this order. Firstly, the $\mathrm{p}^{\mathrm{H}}$ of the distilled water was measured and was found to be 7.0, secondly, the same distilled water on another beaker was subjected to the addition of Potassium Hydroxide (KOH) in pellets and the $\mathrm{pH}$ was raised to 12.3. Thirdly, another distilled water poured on another beaker which was subjected to the addition of Sulphuric Acid $\left(\mathrm{H}_{2} \mathrm{SO}_{4}\right)$ in drop and the $\mathrm{p}^{\mathrm{H}}$ dropped to 1.7 , hence the concentration of HCL was reduced by adding more distilled water until the $\mathrm{p}^{\mathrm{H}}$ read 2.4. Consequently, the following $\mathrm{p}^{\mathrm{H}}$ values was used as water to be used in formulating the three emulsion samples (2.4, 7 and 12.3). Step 2: $100 \mathrm{ml}$ of crude oil was measured with the aid of a $250 \mathrm{ml}$ capacity measuring cylinder, then $2 \mathrm{ml}$ of the surfactant was added to the crude oil and properly mixed with a laboratory mixer for four (4) minutes until same $100 \mathrm{ml}$ of distilled water (with $\mathrm{pH}$ value of 7) was added to crude oil in the mixer. Crude oil and water ratio is $50: 50(\mathrm{v} / \mathrm{v})$. Similarly, the other water with $\mathrm{pH}$ values of 2.3 and 12.8 was also formulated with the process discussed above.

Procedure for Emulsion breaking (demulsification) process. This is a process of injecting chemical demulsifiers or called emulsion breakers to the emulsion samples under study. In this work, $3 \mathrm{ml}$ of 1M HCL was used as emulsion breaker for the three sample used for investigating effect of API gravity while $3 \mathrm{ml}$ of Glycerol was used to break Usan crude ascertain influence of $\mathrm{pH}$. A stop watch is activated upon injection of the demulsifier; volume of oil recovered was recorded against time.

\section{RESULTS AND DISCUSSION}

The results obtained after injecting emulsion breaker 1.0M of HCL to the emulsion is presented below. Oil was seen on all the samples and oil volume was been recorded while water was still trapped within the emulsion. There was a creamy emulsion under the crude oil emulsion.

The result of volume of oil recovered from the Usan, Atala, and Oredo formulated emulsion samples, having an API gravity of 27.4, 34.0, and 45.0 respectively with time in minutes. The experiment ran for almost 6 days after having a constant volume of oil.

Figure 1 above represents a plot of an increasing recovered (Usan) volume of oil during the demulification or emulsion breakdown of the emulsified Usan crude oil sample with time in minutes. On the introduction of the glycerol in the usan formulated emulsion from the chart, a high oil volume ratio was recovered on the early start and the breakdown process rate is seen to decrease with minute's time away from the start time. 


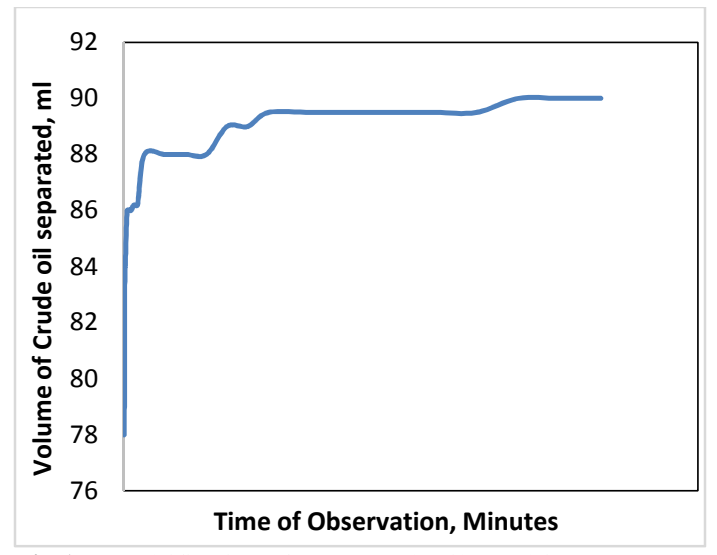

Fig 1 Demulsification of Usan Crude oil Emulsion

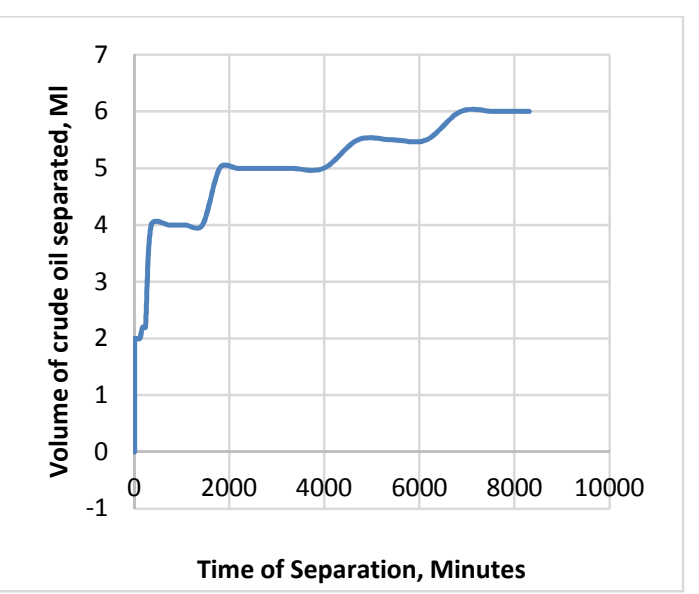

Fig 2 Demulsification of Atala Crude oil Emulsion

The figure 2 above represents a plot of the recovered volume of oil during the demulification or emulsion breakdown of the emulsified Atala crude oil sample with time in minutes. On the introduction of the glycerol to the Atala formulated emulsion. From the figure 2, a small fraction of oil volume was recovered from the sample on the early start and the breakdown process was almost uniform with minute time

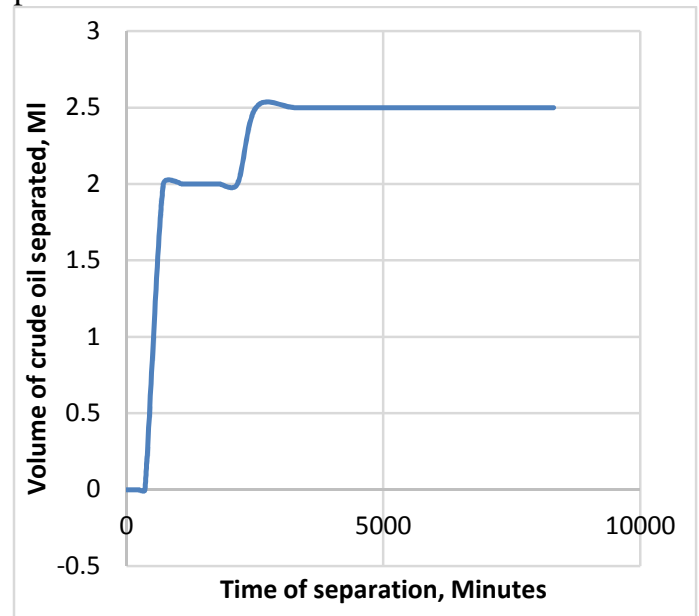

Fig 3 Demulsification of Oredo Crude oil Emulsion
Figure 3 above represents a plot of the recovered (Oredo tank B) volume of oil during the demulification or emulsion breakdown of the emulsified crude oil sample with time in minutes. On the introduction of the glycerol in the Oredo Tank B formulated emulsion. From the figure 3, at first there exist no volume of oil recovered until after a meaningful minutes, also the rate of the emulsion breakdown was extremely slow for the OredoTank B

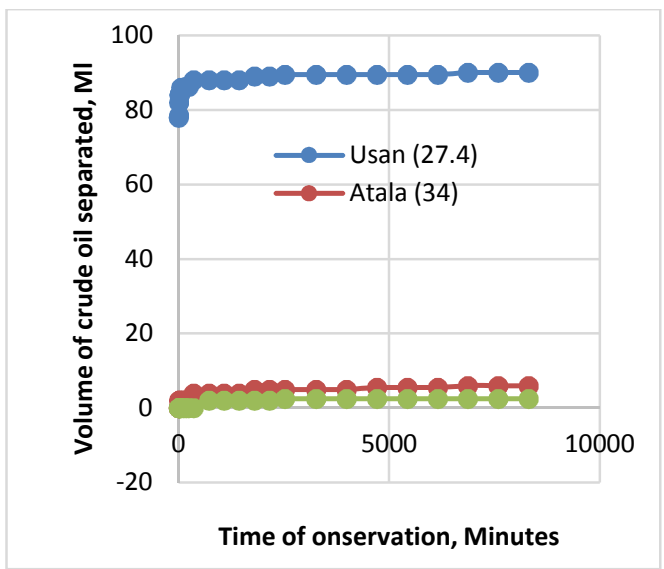

Fig 4 Demulsification of combined Usan, Atala\&Oredo Crude oil Emulsions

The figure 4 above represent the various oil volumes recovered from the three samples and from the above chart the formulated Usan emulsion have an higher oil recovery, whose emulsion stability is low compared to that of Atala and Oredo having a lower volume of oil

Effect of $\mathrm{pH}$ on the stability of water in oil emulsion: The three emulsions formulated with varying water $\mathrm{pH}$ values were demulsified and the results of the emulsion breaker are tabulated below. Volume of oil recovered was recorded against time. The experiment was allowed to run for two days after having a constant volume of oil.

The results of volume of oil recovered at varying $\mathrm{pH}$ values for the Usan crude samples, using a $3 \mathrm{ml}$ glycerol for demulsifying the prepared $200 \mathrm{ml}$ of formulated Usan emulsion with varying $\mathrm{pH}$ concentration with time in minute and the experiment ran for almost two days (42hours) after having a constant volume of oil.

The figure 5 above represent the plot of various oil volumes recovered from the varying $\mathrm{pH}$ samples with time and from the above chart the acidized prepared emulsion have the least stability before the neutral $\mathrm{pH}$ then alkaline prepared emulsion is more stable i.e have a higher stability hence produced less volume of oil. 


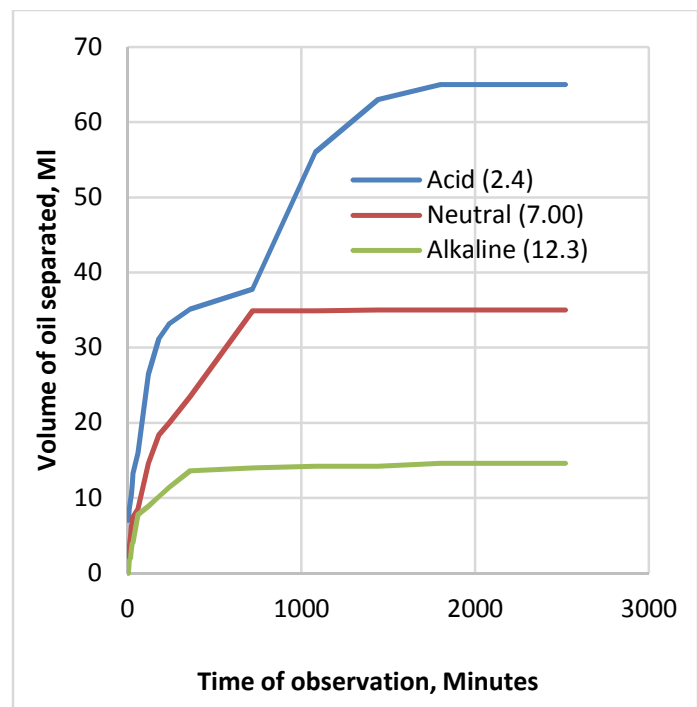

Fig 5: Effect pf pH on the stability of water-in-oil Emulsion

Emulsion with varying API gravity: From the results presented above, API value of crude affects emulsion breaking process. After six (6) days of a demulsification process, Usan crude oil emulsion with API gravity of 27.4 had $90 \mathrm{ml}$ of oil separated. Under the same condition, Atala with API gravity of 34 had $6 \mathrm{ml}$ separated and Oredo tank B crude oil emulsion with API gravity of 45 had $2.5 \mathrm{ml}$ of crude oil separated. The means light crude oil with high API gravity values are more stable than heavier crude oil with low API gravity values.

Emulsion with varying $p H$ values: Based on the results presented above, $65 \mathrm{ml}$ of crude oil was recovered from the emulsion when the $\mathrm{pH}$ is 2.4 (acidic), $35 \mathrm{ml}$ of crude oil was recovered when the emulsion formulated with distilled water with a $\mathrm{pH}$ of 7 (neutral) while $14.6 \mathrm{ml}$ was recovered when the $\mathrm{pH}$ is 12.3 (alkaline).
Conclusion: From the result of the experiment presented above, it clearly shows that API gravity have an overall influence on the stability of water-in-oil emulsion. The results show that Usan crude with lower API gravity broke out $90 \mathrm{ml}$ of oil in 138.5 hours (about six days) while Atala and Oredo broke out $6.0 \mathrm{ml}$ and $2.5 \mathrm{ml}$ respectively. This shows that the lower the API gravity the much lower the stability. Also, the results collected from the Usan when subjected at varying $\mathrm{pH}$ values shows that crude oil emulsion is more stable when $\mathrm{pH}$ is high.

\section{REFERENCE}

Joblom, SJ; (2001). Emulsion: Stabilizing agents. Encyclopedic Hand Book of Emulsion Technology New York Marcel Dekker.

Ashrafizade, SN; Kamran, M (2010). Emulsification of heavy crude oil in water for pipeline transportation. J. Petrol. Sci. Engineer. 71: 205 211

Shadi,WH; Mamdouh, TG;Nabil, E(2010). Heavy crude oil viscosity reduction and rheology for pipeline transportation J. Fuel. 89: 1095-1100

Mingyuan, L; Christy, AA; Sjoblom, J (1992). Emulsion-A Fundamental and Practical Approach, J. Sjoblom, ed., NATO ASI Ser,

Kumar,HV; Woltornist, SJ: Adamson, DH (2016). Fractionation and characterization of grapheme oxide by oxidation extent through emulsion stabilization. Carbon.98: 491-495

Reza,Z ;Abdullah, C; Said, SHE ; Alireza, P (2016), Demulsification Techniques of water in oil and oil in water emulsions in petroleum industry, Separate. Purif. Technol. 1701 October 2016, 377-407. 